\title{
A Multifunctional Hybrid[4]arene-Based Macrocyclic Amphiphile: Self-Assembly, Tunable LCST Behavior, and Construction of Fluorescent Nanoparticles for Cell Imaging
}

\author{
Ming Li, Hongzhen Bai, Li Shao, ${ }^{*}$ and Bin Hua* \\ Department of Chemistry, Zhejiang University, Hangzhou 310027, P. R. China. \\ Email address: lishao@zju.edu.cn; huabin@zju.edu.cn.
}

\section{Supporting Information (21 pages)}

1. Materials and methods

S3

2. Synthesis of macrocyclic amphiphile $\boldsymbol{H}$

S6

3. SEM studies of $\boldsymbol{H}$ below and above its LCST

4. DLS studies of amphiphilic $\boldsymbol{H}$ with different concentrations in water

5. TEM studies and model representation of the self-assembly structure of $\boldsymbol{H}$

6. Lower critical solution temperature studies of $\boldsymbol{H}$

7. ${ }^{1} H$ NMR investigation of $\boldsymbol{H}$ in the presence and absence of $\mathrm{K}^{+}$

8. 2D NOESY spectrum of the host-guest complex $\boldsymbol{H} \supset \boldsymbol{G}$ in $\mathrm{D}_{2} \mathrm{O}$

9. ITC investigations of host-guest complexation between $\boldsymbol{H}$ and the dye $\boldsymbol{G}$

10 Electrospray ionization mass spectrum of a aqueous solution of $\boldsymbol{H}$ and $\boldsymbol{G}$

11 Investigation of the host-guest interaction between $\boldsymbol{H}$ and $\boldsymbol{G}$ in $\mathrm{NaCl}$ $(0.9 \%)$ at $37^{\circ} \mathrm{C}$

$12 U V$-vis study of $\boldsymbol{H} \supset \boldsymbol{G}$ in water

13 Photograph of the solution containing $\boldsymbol{H} \supset \boldsymbol{G}$ upon excitation at $365 \mathrm{~nm}$ using a UV lamp 
14 Confocal images of $3 T 3$ and HeLa after incubation with $\boldsymbol{H} \supset \boldsymbol{G}$ and $\boldsymbol{G}$

15 Cytotoxicity evaluation

16 References

$\mathrm{S} 21$ 


\section{Materials and methods}

All reagents including guest compound $\mathbf{G}$ were commercially available and used as supplied without further purification. Solvents were either employed as purchased or dried according to procedures described in the literature. Compounds $\mathbf{H}_{\mathbf{a}}$ and $\mathbf{H}_{\mathbf{b}}$ were prepared according to published literature procedures. ${ }^{\text {S1-S2 }}$ NMR spectra were recorded with a Bruker Avance DMX 600 spectrophotometer or a Bruker Avance DMX 500 spectrophotometer or a Bruker Avance DMX 400 spectrophotometer using the deuterated solvent as the lock and the residual solvent or TMS as the internal reference. Low-resolution electrospray ionization mass spectra (LRESI-MS) were obtained on a Bruker Esquire 3000 Plus spectrometer (Bruker-Franzen Analytik GmbH Bremen, Germany) equipped with an ESI interface and an ion trap analyzer. High-resolution electrospray ionization mass spectrum (HRESI-MS) was obtained on IonSpec 4.7 Tesla FTMS. Scanning electron microscopy (SEM) investigations were carried out on a JEOL 6390LV instrument operating at an energy of $15 \mathrm{Kev}$ or $20 \mathrm{Kev}$. Transmission electron microscopy (TEM) investigations were carried out on a HT-7700 instrument. Dynamic light scattering (DLS) measurements were carried out on a Malvern Nanosizer S instrument at different temperature. UV-vis absorption spectra were taken on a Shimadzu UV-2550 UV-vis spectrophotometer. The fluorescence experiments were conducted on a RF-5301 spectrofluorophotometer (Shimadzu Corporation, Japan). The critical aggregation concentration (CAC) values were determined on a KRUSS DAS100 instrument. 2D NOESY NMR spectra were collected on a Bruker Avance DMX-500 spectrometer with internal standard TMS. Isothermal titration calorimetric (ITC) experiments were performed on a VP-ITC micro-calorimeter.

Dynamic Light Scattering (DLS) Studies. Different concentrations of solutions of amphiphilic $\mathbf{H}$ and host-guest complex $\mathbf{H} \supset \mathbf{G}$ were left to stand for hours and further used for DLS tests. The diameters of the assemblies were then measured on a Malvern Nanosizer $\mathrm{S}$ instrument at different temperature for specific purpose. 
Isothermal titration calorimetry (ITC) experiments. ITC is a useful tool to study the association constant $\left(K_{\mathrm{a}}\right)$, stoichiometry of host-guest complexes and thermodynamic parameters (enthalpy change $\Delta H^{\circ}$ and entropy change $\Delta S^{\circ}$ ). In this article, the experiments were performed in aqueous solution at $303.15 \mathrm{~K}$ under the procedure of 28 sequential injections ( $2 \mathrm{~mL}$ per injection) of a $\mathbf{G}$ solution $(20.00 \mathrm{mM})$ into a $\mathbf{H}$ solution $(1.00 \mathrm{mM})$, and the results were obtained from a VP-ITC micro-calorimeter.

UV-vis and fluorescence titration tests. In this study, the UV-vis absorption spectrum of the host-guest complex $\mathbf{H} \supset \mathbf{G}$ was performed on a Shimadzu UV-2550 UV-vis spectrophotometer by measuring the mixture of $\mathbf{H}\left(5.00 \times 10^{-5} \mathbf{M}\right)$ and $\mathbf{G}$ $\left(5.00 \times 10^{-5} \mathrm{M}\right)$ in aqueous solution at room temperature, and was conducted to gain the location of the maximum absorption peak as well. The fluorescence intensities of $\mathbf{G}(1.00 \mathrm{mM})$ in the presence of different concentrations of amphiphilic $\mathbf{H}$ (from 0 to $7.35 \mathrm{mM}$ ) were measured on a RF-5301 spectrofluorophotometer under the condition of room temperature $\left(\lambda_{\mathrm{ex}}=450 \mathrm{~nm}, \lambda_{\mathrm{em}}=613 \mathrm{~nm}\right)$.

SEM and TEM sample preparation. SEM samples and TEM samples were prepared by drop-coating the solution onto silicon wafers and carbon-coated copper grids via the drying methodology, respectively.

Cell Culture. HeLa and 3T3 cells were cultured in Dulbecco's modified Eagle's medium (DMEM) containing $10 \%$ fetal bovine serum (FBS) and $1 \%$ penicillin/streptomycin. Cells grew as a monolayer and were detached upon confluence using trypsin $(0.5 \% \mathrm{w} / \mathrm{v}$ in PBS). The cells were harvested from cell culture medium by incubating in trypsin solution for $5 \mathrm{~min}$. The cells were centrifuged, and the supernatant was discarded. A $3 \mathrm{~mL}$ portion of serum-supplemented DMEM was added to neutralize any residual trypsin. The cells were resuspended in serum-supplemented DMEM at a concentration of $1 \times 10^{4}$ cells/mL. Cells were cultured at $37{ }^{\circ} \mathrm{C}$ and $5 \% \mathrm{CO}_{2}$. 
Evaluation of Cytotoxicity. The cytotoxicity of $\mathbf{H}, \mathbf{G}$ and $\mathbf{H} \supset \mathbf{G}$ against HeLa and 3 T3 cells was determined by 3-(4,5-dimethylthiazol-2-yl)-2,5-diphenyl tetrazolium bromide (MTT) assays in a 96-well cell culture plate. All solutions were sterilized by filtration with a $0.22 \mu \mathrm{m}$ filter before tests. HeLa and $3 \mathrm{~T} 3$ cells were seeded at a density of $1 \times 10^{4}$ cells/well in a 96-well plate, and incubated for $24 \mathrm{~h}$ for attachment. Cells were then incubated with $\mathbf{H}, \mathbf{G}$ and $\mathbf{H} \supset \mathbf{G}$ at various concentrations for $4 \mathrm{~h}$ and $24 \mathrm{~h}$. After washing the cells with PBS buffer, $200 \mu \mathrm{L}$ of a MTT solution $(0.5 \mathrm{mg} / \mathrm{mL})$ was added to each well. After $4 \mathrm{~h}$ of incubation at $37{ }^{\circ} \mathrm{C}$, the MTT solution was removed, and the insoluble formazan crystals that formed were dissolved in $100 \mu \mathrm{L}$ of dimethylsulfoxide (DMSO). The absorbance of the formazan product was measured at $570 \mathrm{~nm}$ using a spectrophotometer (Bio-Rad Model 680). Untreated cells in media were used as a control. All experiments were carried out with five replicates.

\section{In Vitro Cell Accumulation of HدG Determined by Confocal Laser Scanning}

Microscopy (CLSM). HeLa and 3T3 cells were treated with HつG (the concentration was kept at $25 \mu \mathrm{M}$ in the culture medium at $37{ }^{\circ} \mathrm{C}$ for $4 \mathrm{~h}$. The cells were washed three times with PBS and fixed with fresh $4.0 \%$ formaldehyde at room temperature for 15 min. After washing with PBS, the core and plasma membrane of the treated cells were stained with DAPI (1 $\mu \mathrm{g} / \mathrm{mL}, 5 \mathrm{~min})$ and FITC $(5 \mu \mathrm{g} / \mathrm{mL}, 10 \mathrm{~min})$. The images were taken using a confocal laser scanning microscope (CLSM). 
2. Synthesis of macrocyclic amphiphile $\boldsymbol{H}$

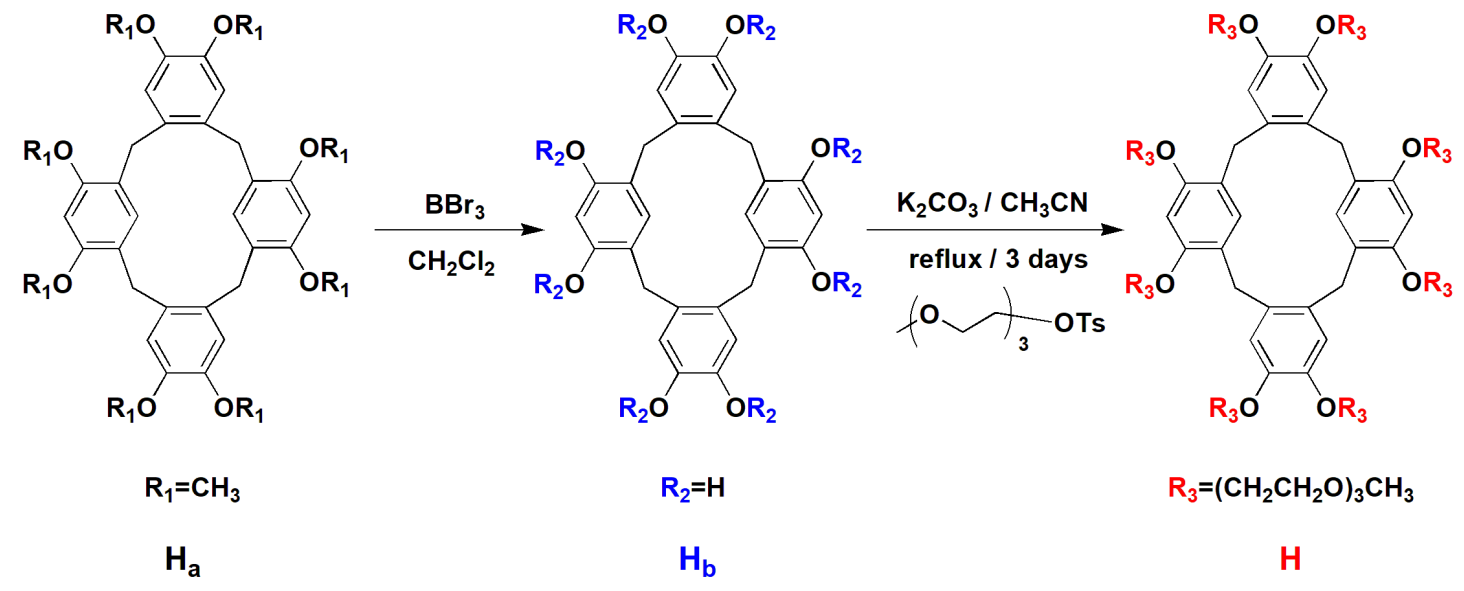

Scheme S1. Synthetic route to $\mathbf{H}$.

$\mathbf{H}_{\mathbf{a}}{ }^{\mathrm{S} 1}$ and $\mathbf{H}_{\mathbf{b}}{ }^{\mathrm{S} 2}$ were successfully synthesized according to the previously reported literature procedures, respectively. For the synthesis of $\mathbf{H}, \mathbf{H}_{\mathbf{b}}(2.20 \mathrm{~g}, 4.50 \mathrm{mmol})$ was first dissolved in the solution of $\mathrm{CH}_{3} \mathrm{CN}$ (300 mL). And then, $\mathrm{K}_{2} \mathrm{CO}_{3}(6.22 \mathrm{~g}, 45.00$ mmol) was added and the reaction mixture was stirred at room temperature. Later, triethylene glycol monomethyl ether mono-p-tosylate $(10.34 \mathrm{~g}, 45.00 \mathrm{mmol})$ was added and the reaction mixture was stirred under nitrogen atmosphere at reflux for 3 days. The solvent was evaporated through a rotary steamer, and the residue was dissolved in $\mathrm{CH}_{2} \mathrm{Cl}_{2}$, further washed with water $(100 \mathrm{~mL})$ and saturated $\mathrm{NaCl}$ solution $(100 \mathrm{~mL})$. The organic phase was collected and dried over anhydrous $\mathrm{Na}_{2} \mathrm{SO}_{4}$ and concentrated to give a crude liquid. The crude product was further purified by column chromatography on silica gel with dichloromethane/methanol $(20: 1 \mathrm{v} / \mathrm{v})$ as the eluent to afford product $\mathbf{H}$ as a light yellow liquid (1.86 g, 25\%). The proton NMR spectrum of $\mathbf{H}$ is shown in Figure S1. ${ }^{1} \mathrm{H}$ NMR $\left(400 \mathrm{MHz}, \mathrm{D}_{2} \mathrm{O}\right.$, room temperature) $\delta(\mathrm{ppm})$ : $6.62(\mathrm{~s}, 4 \mathrm{H}), 6.11(\mathrm{~s}, 2 \mathrm{H}), 5.15(\mathrm{~s}, 2 \mathrm{H}), 4.02-3.88(\mathrm{~m}, 12 \mathrm{H}), 3.80-3.70(\mathrm{~m}, 20 \mathrm{H})$, 3.65-3.59 (m, 16H), 3.57-3.56 (m, 4H), 3.56-3.52 (m, 16H), 3.51-3.48 (m, 16H), 3.43-3.35 (m, 16H), $3.25(\mathrm{~s}, 4 \mathrm{H}), 3.20(\mathrm{~s}, 12 \mathrm{H}), 3.16(\mathrm{~s}, 12 \mathrm{H})$. The ${ }^{13} \mathrm{C}$ NMR spectrum of $\mathbf{H}$ is shown in Figure $\mathrm{S} 2 .{ }^{13} \mathrm{C}$ NMR (100 MHz, $\mathrm{D}_{2} \mathrm{O}$, room temperature) $\delta$ (ppm): 153.57, 146.32, 132.57, 120.75, 118.43, 97.34, 71.63, 69.94, 69.57, 69.38, 68.01, 60.29, 58.00, 30.92. HRESIMS: $m / z$ calcd for $\left[\mathbf{H}+\mathrm{Na}^{+} \mathrm{C}_{84} \mathrm{H}_{136} \mathrm{O}_{32} \mathrm{Na}^{+}\right.$, 1679.8907; found 1679.8913; error 0.4 ppm. 


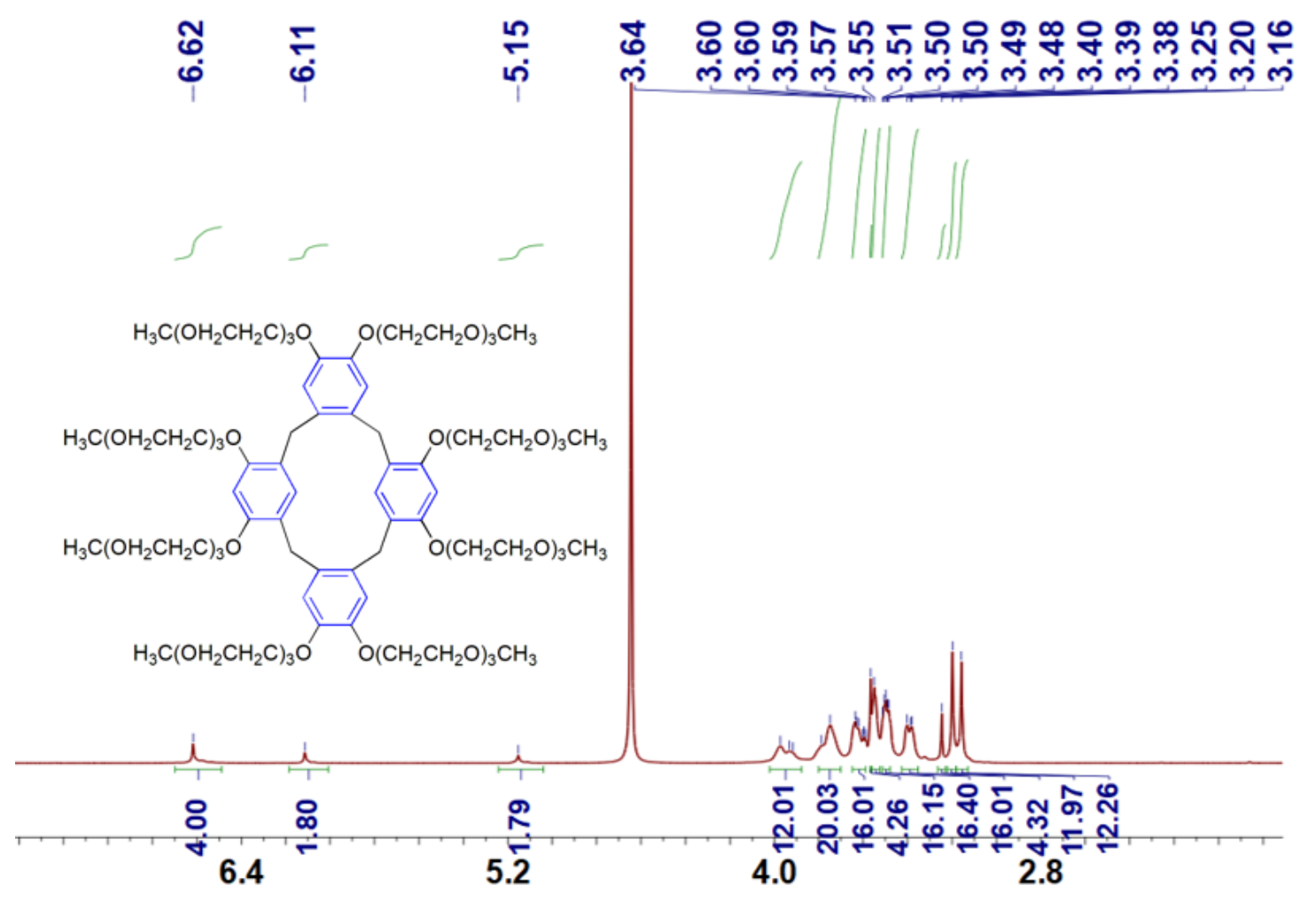

Figure S1. ${ }^{1} \mathrm{H}$ NMR spectrum (400 MHz, $\mathrm{D}_{2} \mathrm{O}$, room temperature) of $\mathbf{H}$.
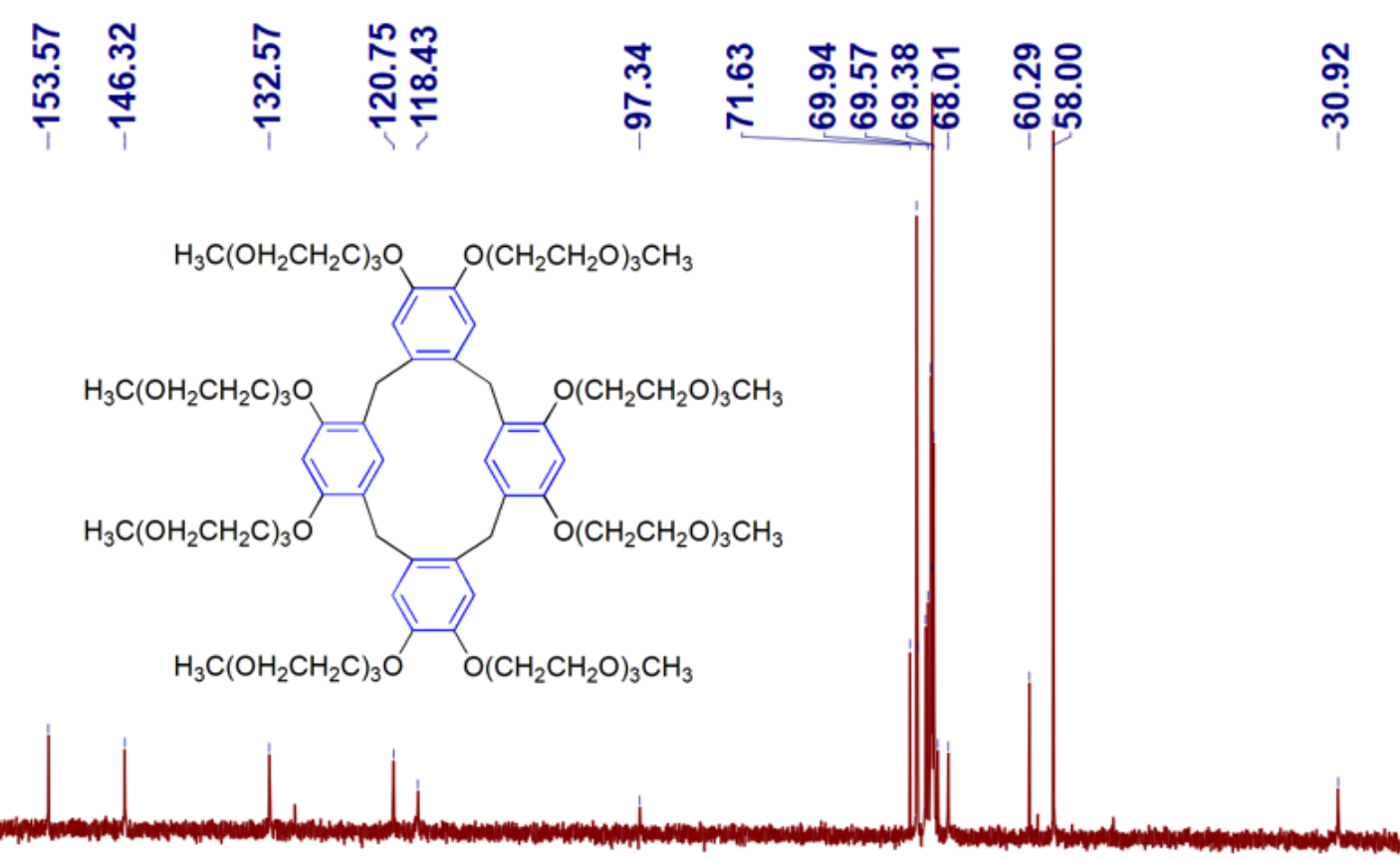

145

120

95

80

65

35

Figure S2. ${ }^{13} \mathrm{C}$ NMR spectrum $\left(100 \mathrm{MHz}, \mathrm{D}_{2} \mathrm{O}\right.$, room temperature) of $\mathbf{H}$. 


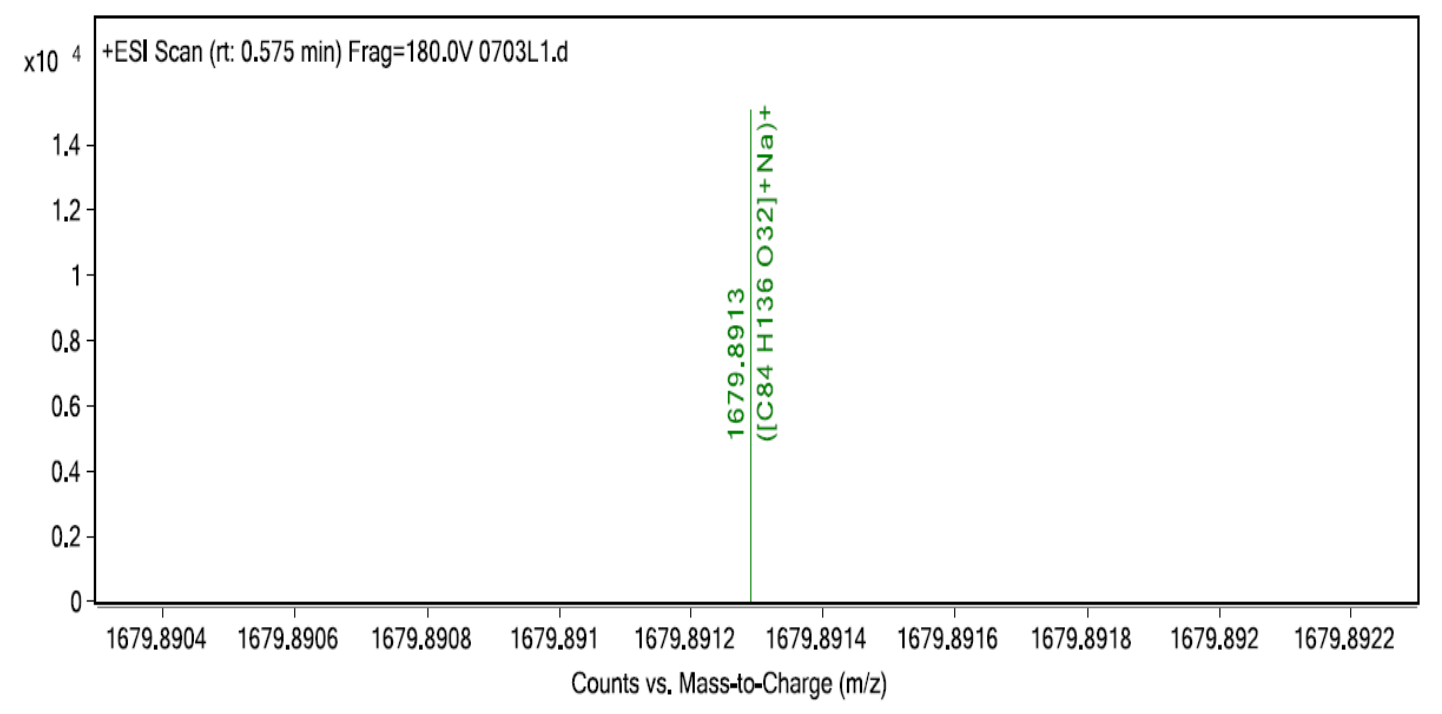

Figure S3. High resolution electrospray ionization mass spectrum of $\mathbf{H}$. Assignment of the main peak: $m / z 1679.8913[\mathbf{H}+\mathrm{Na}]^{+}(100 \%)$. 
(a)

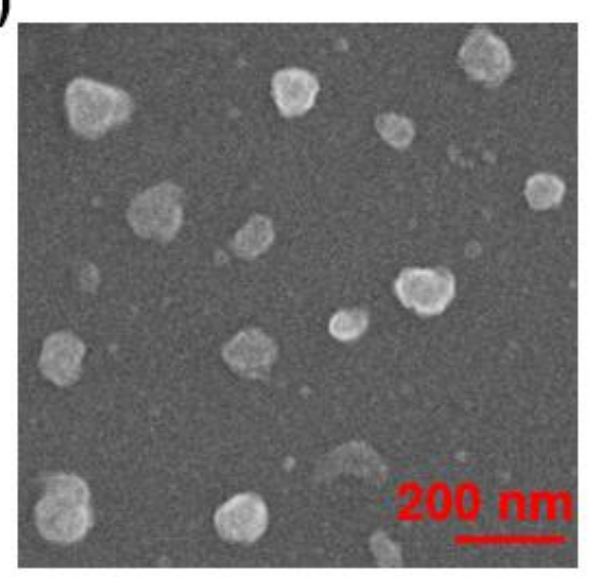

(b)

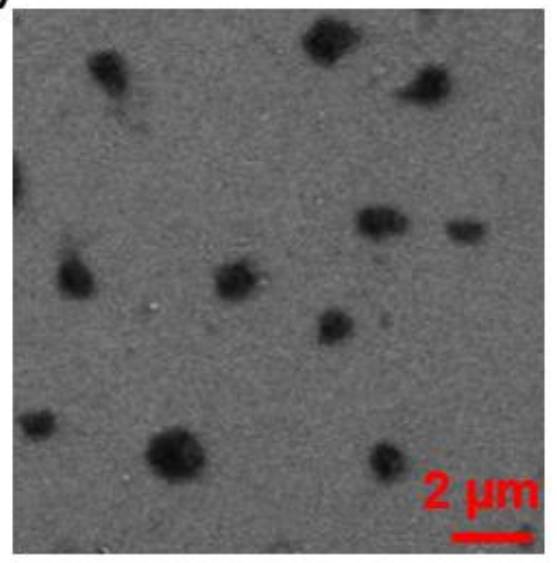

Figure S4. SEM images of amphiphilic $\mathbf{H}(5.00 \mathrm{mM})$ in water: (a) dried at $25.0^{\circ} \mathrm{C}$; (b) dried at $60.0{ }^{\circ} \mathrm{C}$. 
(a)

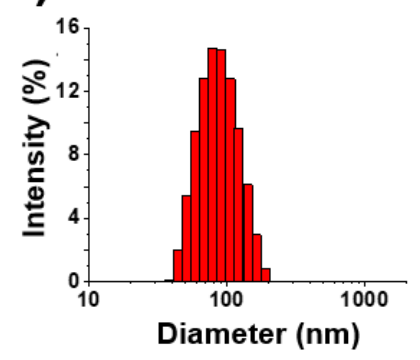

(c)

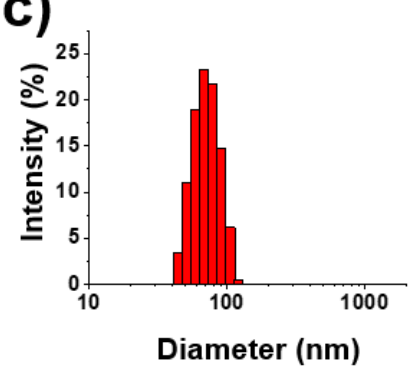

(b)

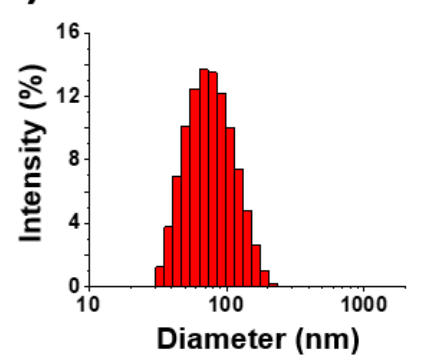

(d)

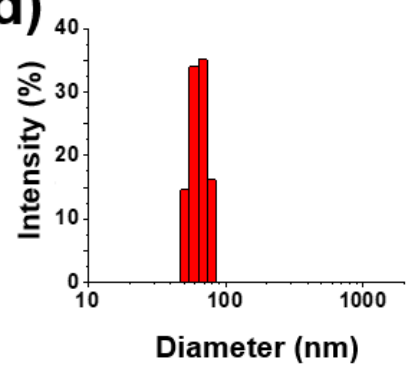

Figure S5. DLS studies of amphiphilic $\mathbf{H}$ at different concentrations: (a) $5.00 \times 10^{-3} \mathrm{M}(\sim 83$ $\mathrm{nm})$; (b) $1.00 \times 10^{-3} \mathrm{M}(\sim 81 \mathrm{~nm})$; (c) $1.00 \times 10^{-4} \mathrm{M}(\sim 72 \mathrm{~nm})$; (d) $1.00 \times 10^{-5} \mathrm{M}(\sim 65 \mathrm{~nm})$. 

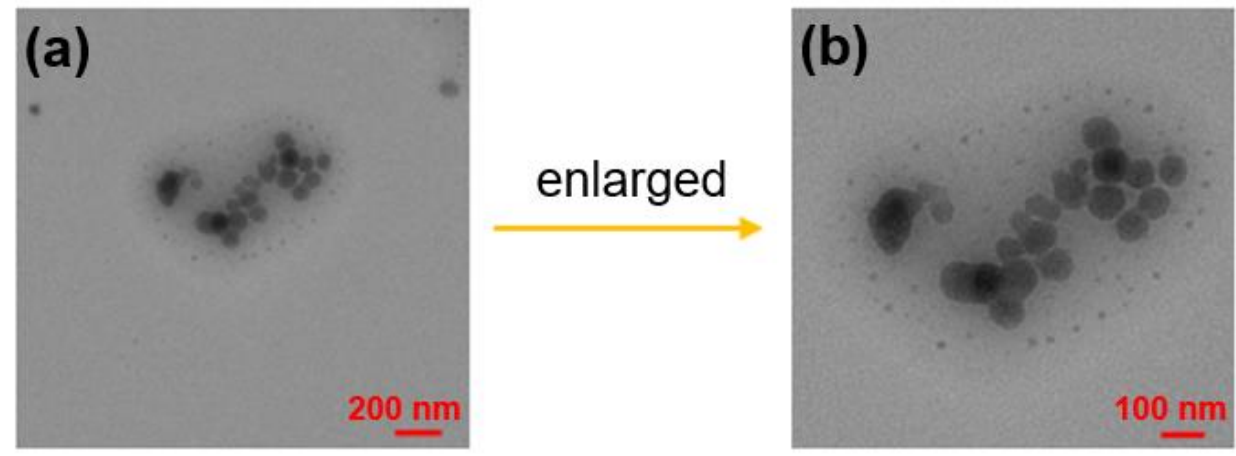

(c)

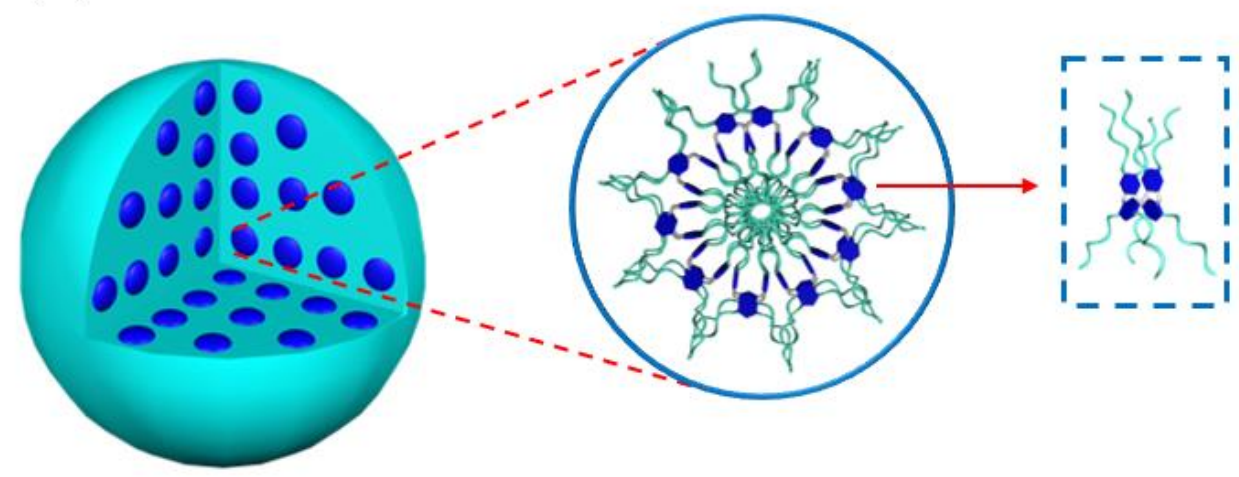

Figure S6. (a) TEM image of amphiphilic $\mathbf{H}(5.00 \mathrm{mM})$ in aqueous solution at room temperature; (b) Enlarged image of (a); (c) The corresponding cartoon model representation of the self-assembly structure of $\mathbf{H}$.

As shown in Figure S6, some micelles and nanoparticles with small sizes can be observed around the self-assembled nanoparticles with large sizes. Therefore we speculated that the self-assembly process might be that amphiphile $\mathbf{H}$ containing tri(ethylene glycol) chains as the hydrophilic portion and benzene rings as hydrophobic part self-assembled into small micelles in water which further aggregated together to form larger nanoparticles. That is, the nanoparticles were formed via agglomeration of small unordered micelles. ${ }^{\text {S3 }}$ 
(a)

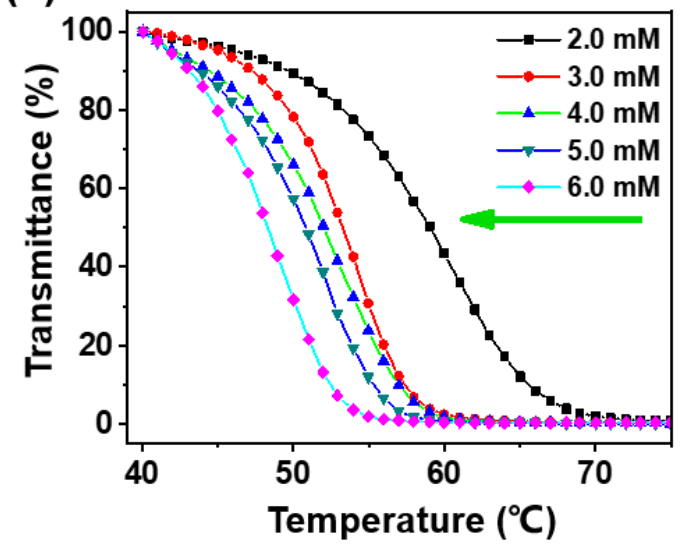

(b)

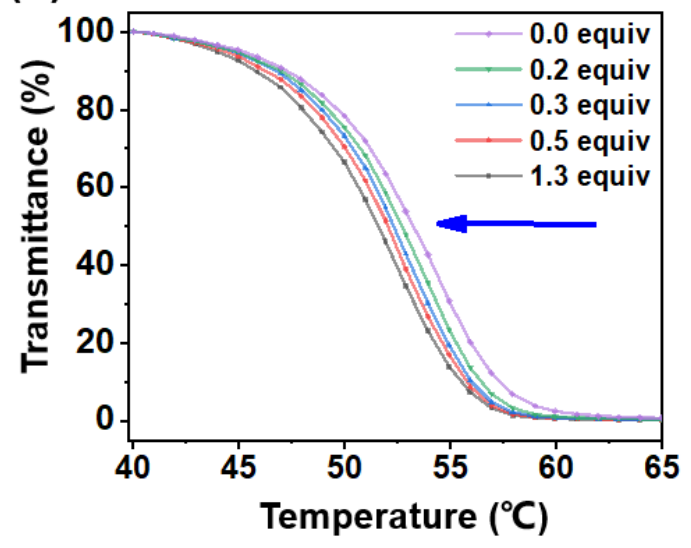

Figure S7. (a) The light transmittance versus temperature for aqueous solution of $\mathbf{H}$ with different concentrations; (b) The light transmittance as a function of temperature upon addition of different molar ratios of $\mathrm{K}^{+}$. 


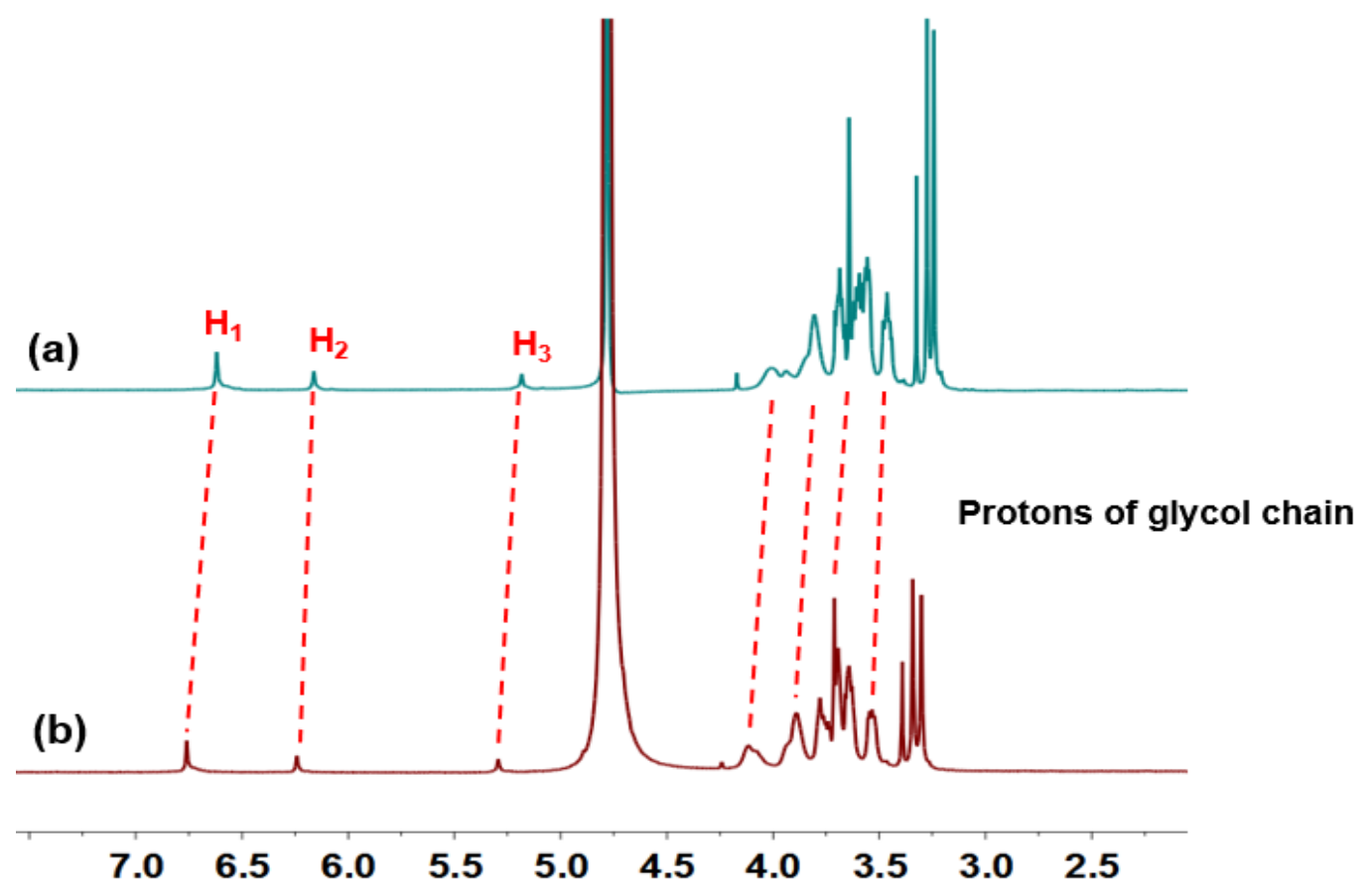

Figure S8. Partial ${ }^{1} \mathrm{H}$ NMR spectrum $\left(400 \mathrm{MHz}, \mathrm{D}_{2} \mathrm{O}, 293 \mathrm{~K}\right)$ of $\mathbf{H}(3.00 \mathrm{mM})$ in the absence (a) and presence (b) of equimolar $\mathrm{K}^{+}$. 
8. 2D NOESY spectrum of the host-guest complex $\boldsymbol{H} \supset \boldsymbol{G}$ in $\mathrm{D}_{2} \mathrm{O}$

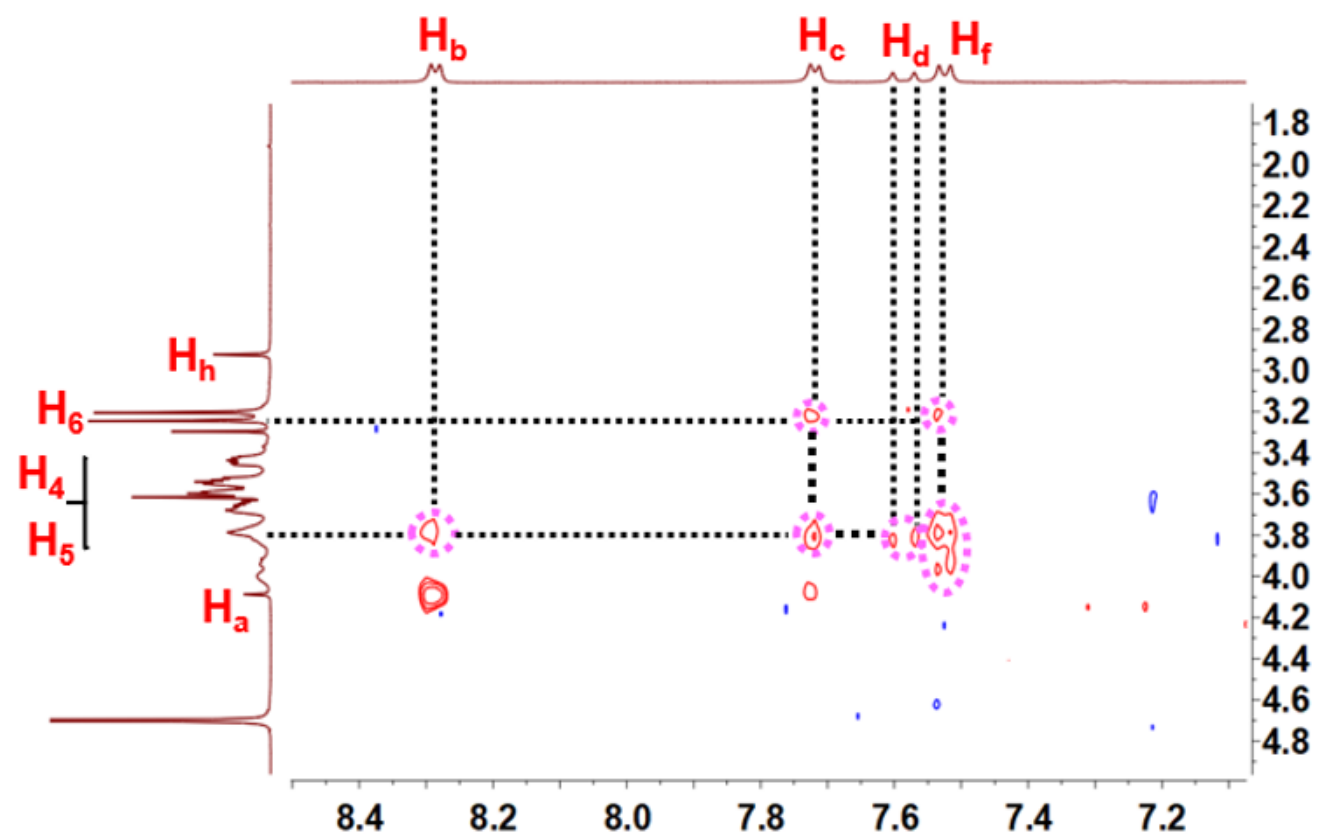

Figure 59. Partial 2D ${ }^{1} \mathrm{H}-{ }^{1} \mathrm{H}$ NOESY spectrum of $\mathbf{H} \supset \mathbf{G}\left(500 \mathrm{MHz}, \mathrm{D}_{2} \mathrm{O}\right.$, room temperature).

$[\mathbf{H}]=2.00 \mathrm{mM} .[\mathbf{G}]=2.00 \mathrm{mM}$.

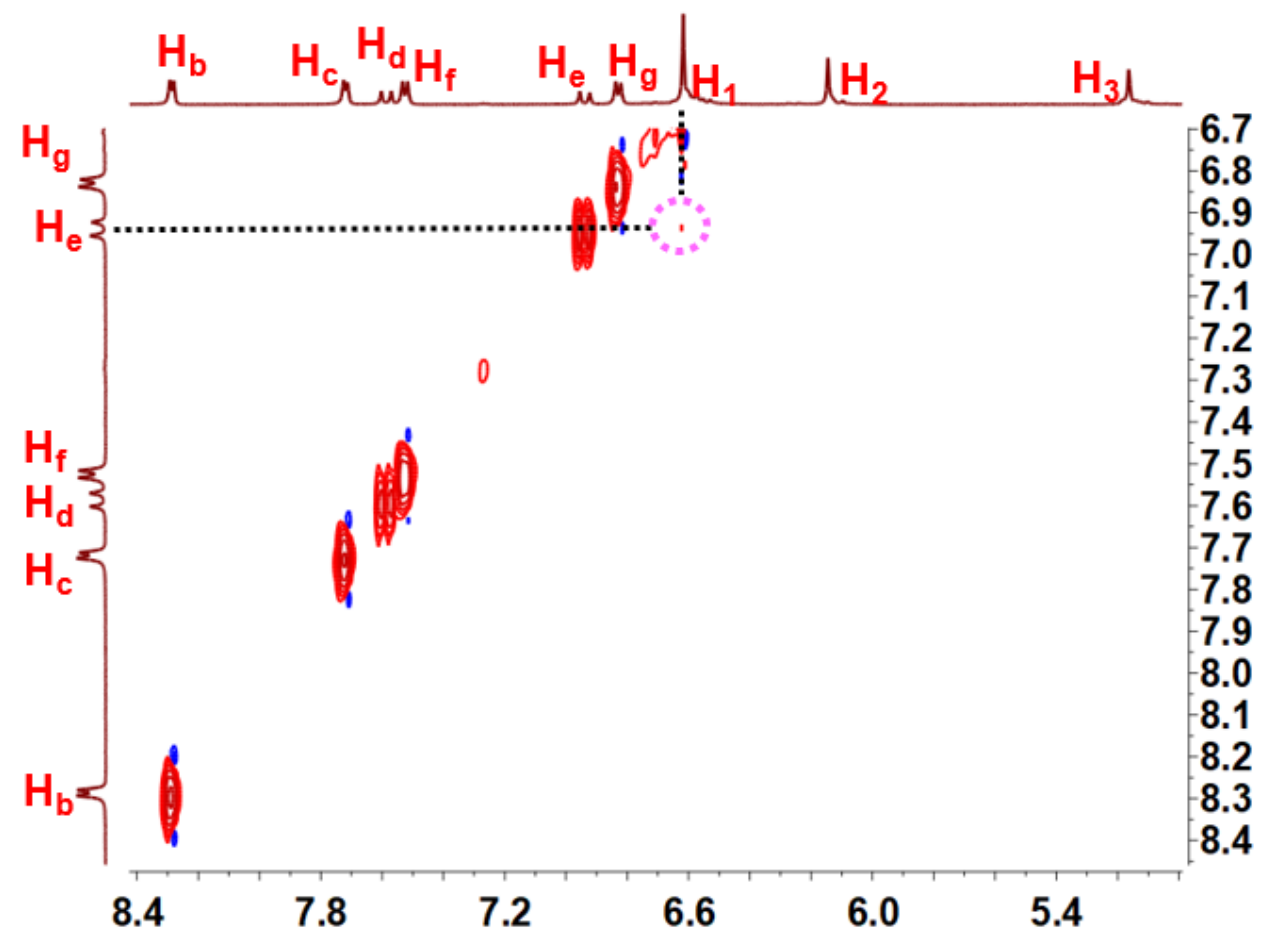

Figure S10. Partial 2D ${ }^{1} \mathrm{H}^{-1} \mathrm{H}$ NOESY spectrum of $\mathbf{H} \supset \mathbf{G}\left(500 \mathrm{MHz}, \mathrm{D}_{2} \mathrm{O}\right.$, room temperature). $[\mathbf{H}]=2.00 \mathrm{mM} .[\mathbf{G}]=2.00 \mathrm{mM}$. 


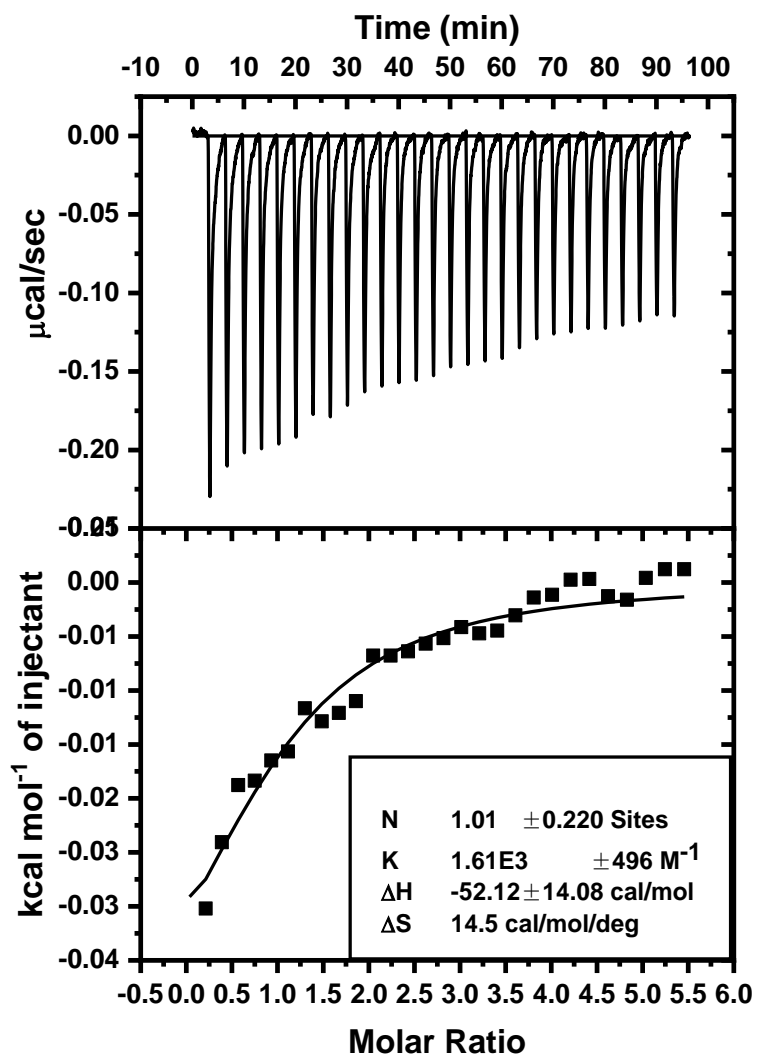

Figure 11. Microcalorimetric titration of $\mathbf{H}$ with $\mathbf{G}$ in aqueous solution at $303.15 \mathrm{~K}$. (top) Raw ITC data for 28 sequential injections ( $2 \mathrm{~mL}$ per injection) of a $\mathbf{G}$ solution $(20.00 \mathrm{mM})$ into a $\mathbf{H}$ solution $(1.00 \mathrm{mM})$. (Bottom) Net reaction heat gained from the integration of the calorimetric traces. 
10. Electrospray ionization mass spectrum of a aqueous solution of $\boldsymbol{H}$ and $\boldsymbol{G}$

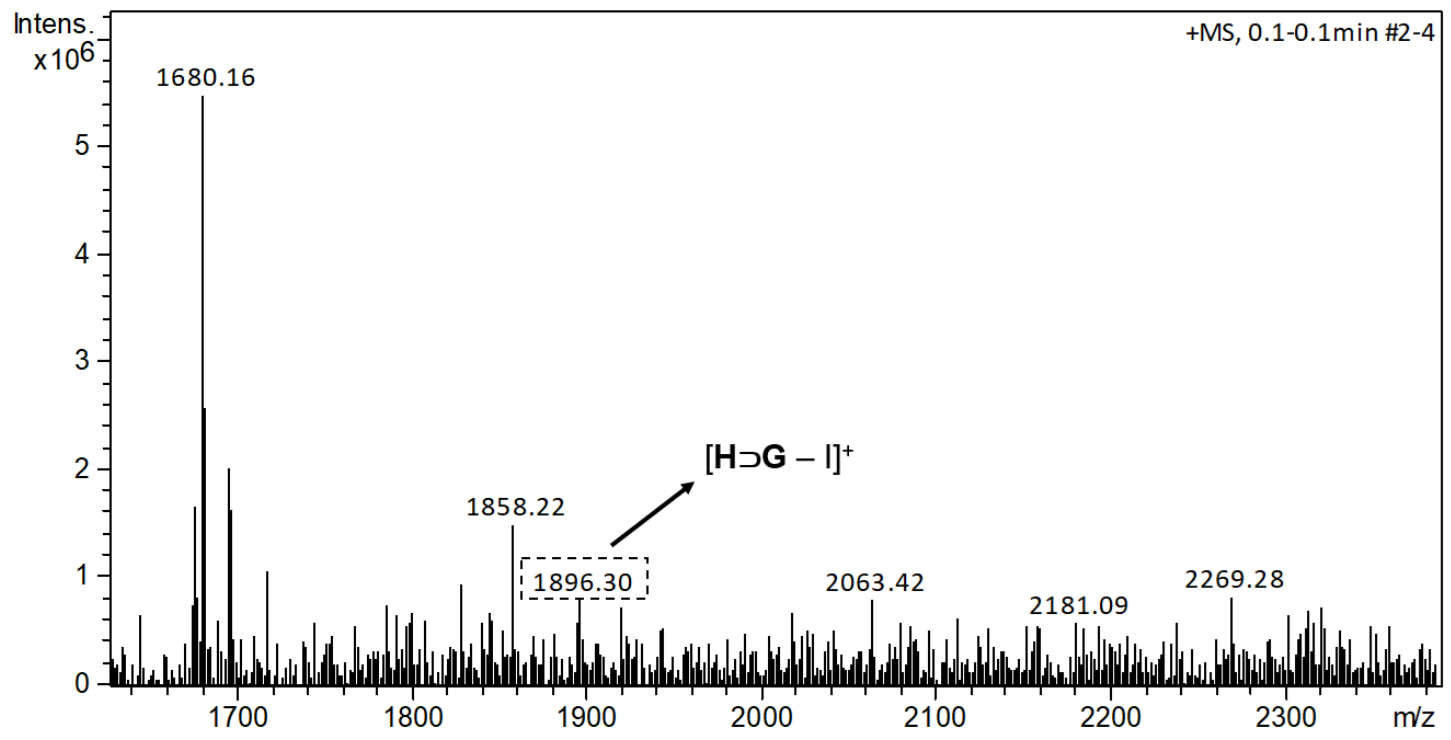

Figure S12. Electrospray ionization mass spectrum of $\mathbf{H} \supset \mathbf{G}$. Assignment of the peak: $\mathrm{m} / \mathrm{z}$ $1896.30[\mathbf{H} \supset \mathbf{G}-\mathrm{I}]^{+}$. 
11. Investigation of the host-guest interaction between $\boldsymbol{H}$ and $\boldsymbol{G}$ in $\mathrm{NaCl}(0.9 \%)$ at $37^{\circ} \mathrm{C}$
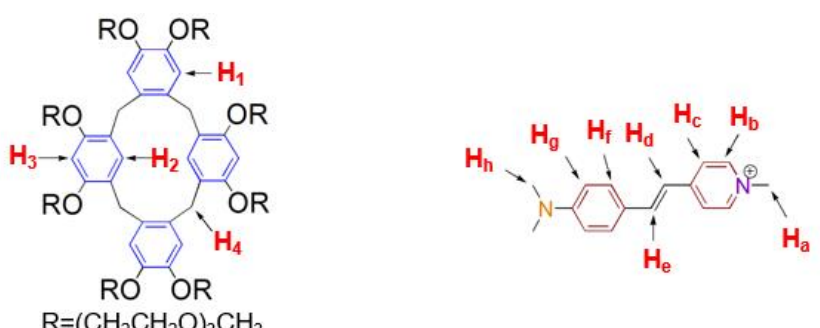

(a)

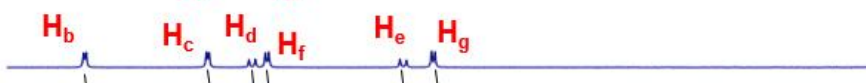

(b)

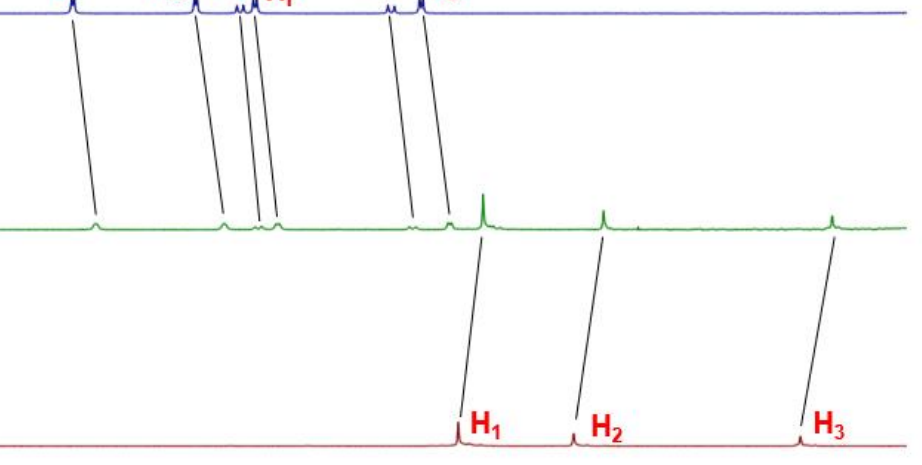

(c)

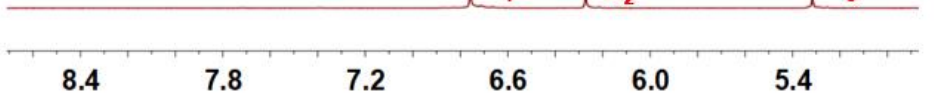

Figure S13. Partial ${ }^{1} \mathrm{H}$ NMR spectra $\left(0.9 \% \mathrm{NaCl}\right.$ in $\left.\mathrm{D}_{2} \mathrm{O}, 310 \mathrm{~K}\right)$ : (a) G; (b) $\mathbf{H}(2.00 \mathrm{mM})$ and $\mathbf{G}(2.00 \mathrm{mM}) ;(\mathrm{c}) \mathbf{H}$. 
12. $U V$-vis study of $\boldsymbol{H} \supset \boldsymbol{G}$ in water

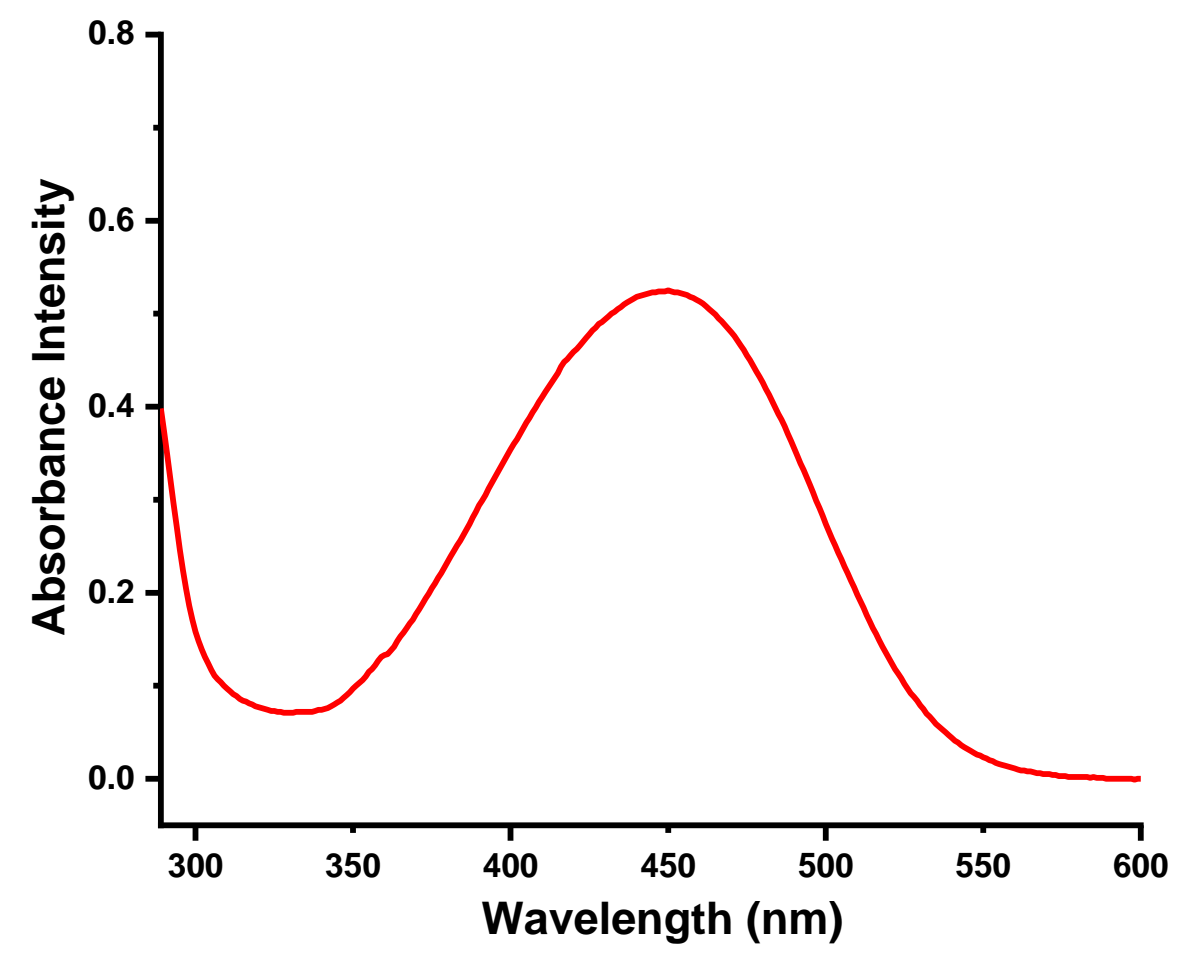

Figure S14. UV-vis absorption spectrum of the mixture of $\mathbf{H}\left(5.00 \times 10^{-5} \mathbf{M}\right)$ and $\mathbf{G}(5.00 \times$ $10^{-5} \mathrm{M}$ ) in aqueous solution. The maximum absorption peak is approximately located at 450 nm. 
13. Photograph of the solution containing $\boldsymbol{H} \supset \boldsymbol{G}$ upon excitation at $365 \mathrm{~nm}$ using a UV lamp

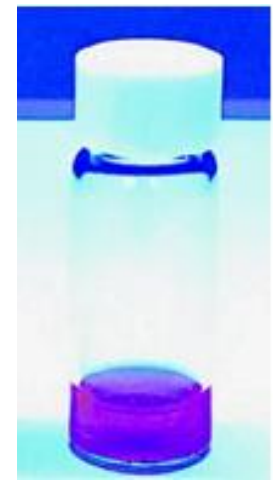

Figure S15. Photograph of the red-emissive solution containing $\mathbf{H} \supset \mathbf{G}$ upon excitation at 365 nm using a UV lamp. 


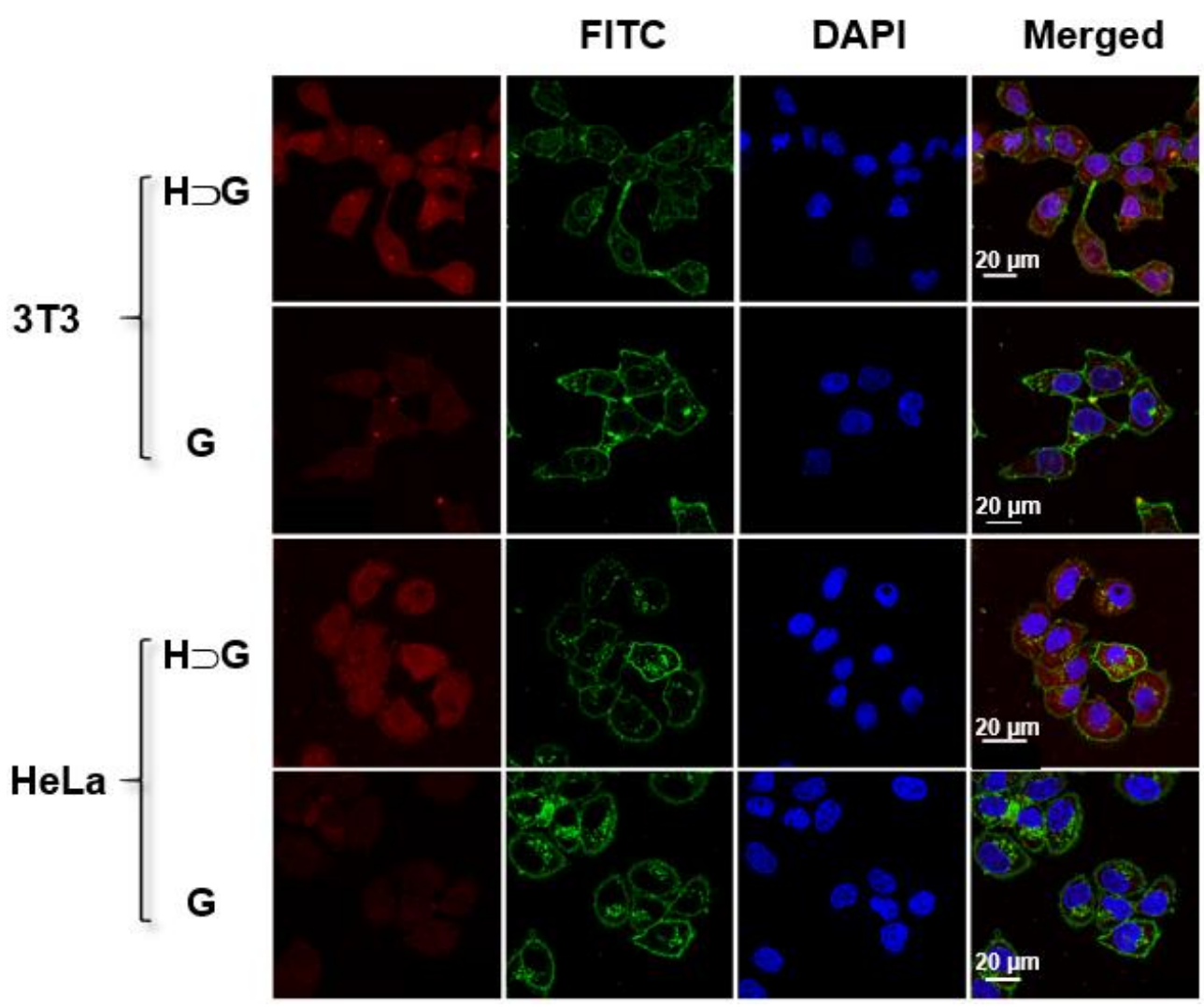

Figure S16. Confocal images of $3 \mathrm{~T} 3$ and HeLa after incubation with the fluorescent nanoparticles self-assembled from $\mathbf{H} \supset \mathbf{G}$ and $\mathbf{G}$, respectively. 
(a)

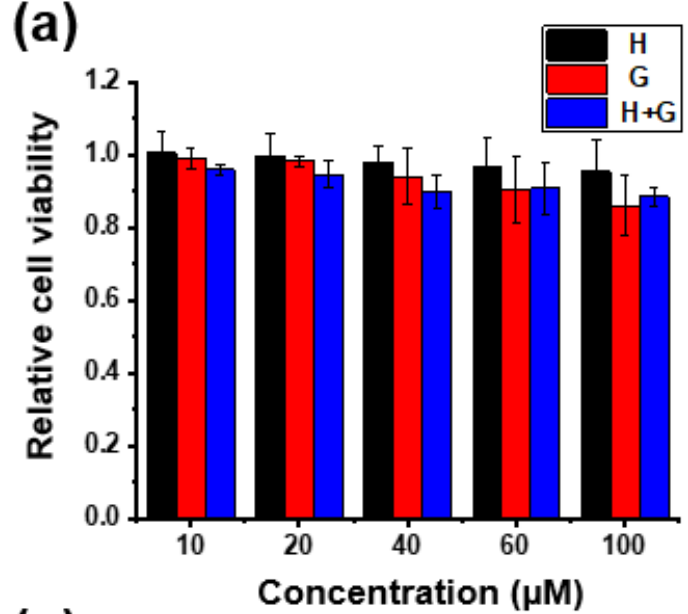

(c)

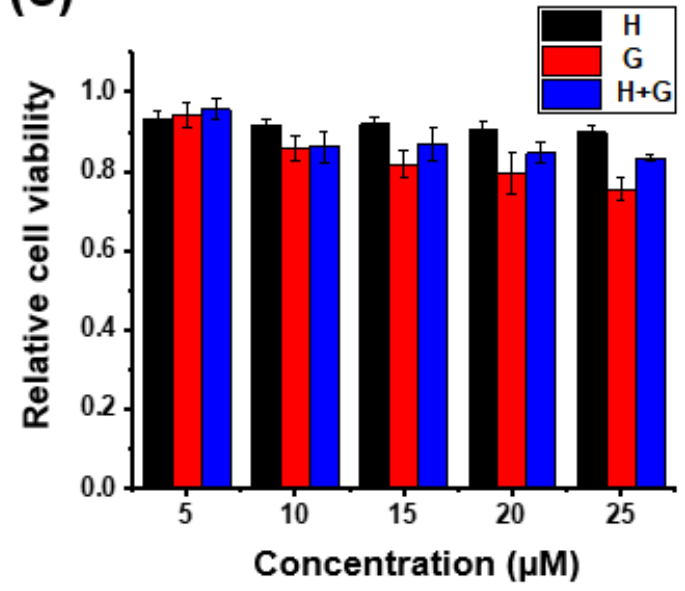

(b)

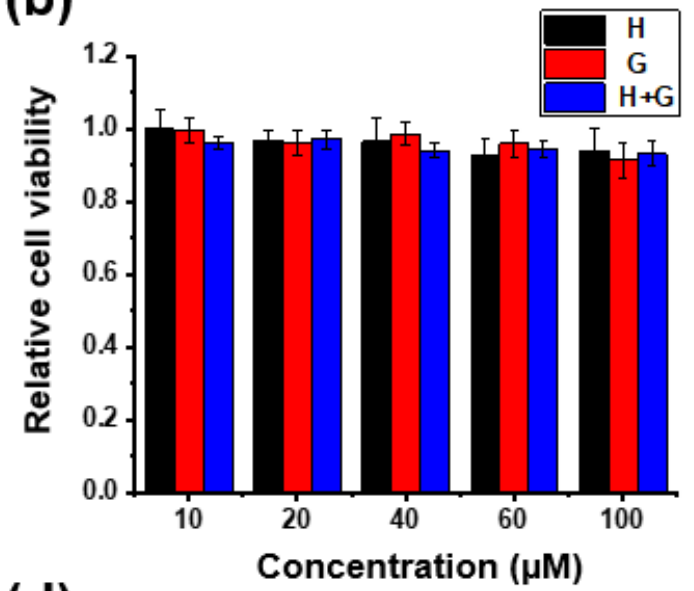

(d)

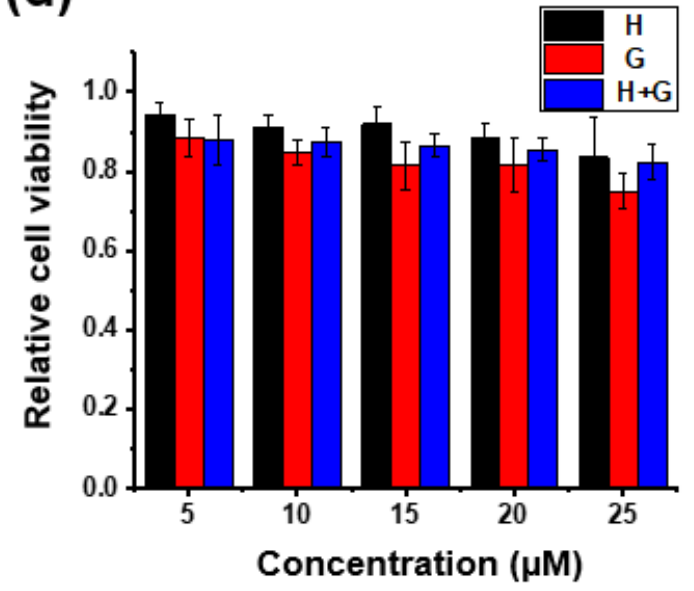

Figure S17. Relative cell viabilities of $3 \mathrm{~T} 3$ cells (a and c) and HeLa cells (b and d) incubated with $\mathbf{H}$ (black column), $\mathbf{G}$ (red column) and $\mathbf{H} \supset \mathbf{G}$ (blue column) at different concentrations for $4 \mathrm{~h}$ ( $\mathrm{a}$ and b) and $24 \mathrm{~h}$ (c and d), calculated from MTT assay, respectively.

\section{References:}

S1. Boinski, T.; Cieszkowski, A.; Rosa, B.; Szumna, A. Hybrid $[n]$ arenes Through Thermodynamically Driven Macrocyclization Reactions. J. Org. Chem. 2015, 80, 3488-3495. S2. Hua, B.; Shao, L.; Zhou, J.; Yu, G. A Water-Soluble Hybrid[4]arene: Synthesis, Host-Guest Complexation and Application in the Construction of a Supra-Amphiphile. New J. Chem. 2016, 40, 4756-4760.

S3. Ma, Y.; Yang, J.; Li, J.; Chi, X.; Xue, M. A Cationic Water-Soluble Pillar[6]arene: Synthesis, Host-Guest Properties, and Self-Assembly with Amphiphilic Guests in Water. RSC Advances 2013, 3, 23953-23956. 